\title{
ENTRE O LEMBRAR E O ESQUECER: A CONSTRUÇÃO DA MEMÓRIA E A VALIDADE DO TESTEMUNHO
}

\author{
Fabrício Paiva Araújo ${ }^{1}$
}

Resumo: A colaboração proposta analisa a representação do "muçulmano" como fator de testemunho da violência no Lager (Campo) em Auschwitz. Em confronto com a construção de uma memória contra o esquecimento, a resistência da vítima como testemunho carrega o paradoxo do indizível. Investiga-se o valor do testemunho na falta do discurso da linguagem, o qual se manifesta no permear entre o dizível e 0 indizível. Observa-se que, apesar da restrição da mente humana em rememorar os traumas vividos durante a Segunda Guerra Mundial, o resgate do passado é de vital importância para que a memória revele a história, a identidade e conserve 0 testemunho.

Palavras-chave: Memória; Testemunho; Linguagem; Muçulmano.

Abstract: The proposed collaboration analyzes the representation of the "Muselmann" as a witness factor of violence in the Lager (field) in Auschwitz. In confrontation with the construction of a memory against forgetting, the victim's resistance as testimony carries the unspoken paradox. It aims to investigates the value of testimony in the absence of speech language, which manifests itself in the permeate between the speakable and the unspeakable. It is observed that, despite the restriction of the human mind in remembering the traumas experienced during the Second World War, the rescue of the past is of vital importance to memory reveals the history, identity and keep the testimony.

Keywords: Memory; Testimony; Language; Muslim.

\footnotetext{
${ }^{1}$ Doutorando em Estudos de Linguagem pelo Centro Federal de Educação Tecnológica de Minas Gerais (CEFET-MG). Mestre em Estudos Literários, área de concentração Literaturas de Expressão Inglesa, pela Universidade Federal de Minas Gerais, com a Dissertação Traumas, memories and hope: remains of the Vietnam War. Membro do Núcleo de Estudos de Guerra e Literatura (NEGUE - UFMG). E-mail: fabriciopaiva@yahoo.com.br.
} 


\section{Introdução}

Uma memória que não se lembrasse do seu morto e o mortal não seria uma memória.

(Derrida, 2003, p. 126)

A Segunda Guerra Mundial se estabelece no século XX como o mais expressivo marco da história das guerras modernas. A magnitude desse conflito bélico gerou incalculáveis perdas materiais e a morte de milhões de seres humanos, tanto nos campos de batalha, como nas cidades e vilarejos de várias nações. $O$ assassinato deliberado de judeus, ciganos, testemunhas de Jeová e homossexuais, promovido por Adolf Hitler e sua Alemanha nazista, era praticado em massa nos campos de extermínio e campos de concentração. Nunca se matou tanto e em tão pouco tempo no mundo moderno. Um conflito sangrento que deixou danos irreparáveis em toda a humanidade. Pouco mais de setenta anos se passaram desde o fim desse evento que assombrou 0 mundo, mas as consequências catastróficas herdadas por esse conflito armado ainda ecoam nos dias de hoje. Os rastros deixados pela guerra persistem em permanecer, transformando a experiência da guerra, seja para soldados ou civis, em algo inesquecível.

A transmissão do horror e da opressão absoluta vivida nas fábricas da morte se tornou um assunto de grande relevância no meio acadêmico, mostrando que as atrocidades herdadas na guerra ultrapassam as fronteiras geográficas e enunciam-se em diferentes vozes e línguas. Há anos a questão do Holocausto - ou Shoah - recebe variadas abordagens em sua representação nas diferentes sociedades humanas, como, por exemplo, nas narrativas historiográficas, na literatura, nos quadrinhos, no cinema, e nas belas artes como um todo. Essas manifestações cooperam para a construção da memória e do testemunho desses sobreviventes, que, apesar da constante aflição da rememoração, revelam suas histórias. Portanto, a obra, É isto um homem?, de Primo Levi, judeu italiano e sobrevivente do campo de extermínio de Auschwitz, é abordada neste artigo para ilustrar o testemunho do sobrevivente. Investiga-se, a partir do depoimento de Levi, a representação do 
"muçulmano" - prisioneiro desumanizado e incapaz de falar - como fator de testemunho da violência no Lager (Campo) em Auschwitz.

\section{A memória e o testemunho}

Em confronto com a construção de uma memória contra o esquecimento, a resistência da vítima como testemunho carrega o paradoxo do indizível. É na falta do discurso da linguagem que se acha o valor do testemunho, o qual se manifesta no permear entre o dizível e o indizível. Observa-se que, apesar da restrição da mente humana em rememorar os traumas vividos durante a guerra, o resgate do passado é de vital importância para que a memória revele a história, a identidade e conserve o testemunho. 0 testemunho é "a forma que com mais pertinência fala em nome de uma época e de um infausto" (MERCADO, 2009, p. 35). A literatura, mais especificamente a narrativa testemunhal, tem a capacidade de lidar com memórias ao permitir diversos pontos de vista e dar voz àqueles que não teriam outro canal de expressão. Em sua obra É Isto um Homem?, Primo Levi oferece insights que nos ajudam a repensar a relação entre memória, trauma e representação literária testemunhal, assim como as questões envolvendo a dor, a revolta e a indignação.

É graças à memória que podemos materializar e conservar a palavra falada, rediscutir o árduo, o obscuro, fazer florescer o real ou o imaginário. $A$ memória nos permite escolher com inteligência os mais fecundos achados que irão contribuir para compor e revelar o testemunho. Para o filósofo italiano Giorgio Agamben, o acontecimento testemunhal realiza-se através da relação de forças locucionais geradas na mediação do poder dizer e do não poder dizer.

O testemunho é uma potência que adquire realidade mediante uma impotência de dizer e uma impossibilidade que adquire existência mediante uma possibilidade de falar. Os dois movimentos não podem nem identificar-se em um sujeito ou em uma consciência, nem sequer separar-se em duas substâncias incomunicáveis. Esta indivisível intimidade é o testemunho (AGAMBEN, 2008, p. 147). 
O testemunho é a língua não arquivável e não enunciável, a língua que sobrevive impulsionada pela possibilidade do dizer ou não dizer. $O$ ato testemunhal é único e merece especial atenção. A narrativa testemunhal carrega interesses e ensinamentos específicos e quase sempre se opõe ao senso geral e universal. Narrar o testemunho exige o compromisso com a análise de si mesmo e com a análise do outro. A complexidade que envolve 0 fluir da narrativa testemunhal e sua utilidade converge para a relação entre o passado e o presente, onde a transmissibilidade das lembranças é essencial para entender as ações do homem perante as experiências que se herda dos acontecimentos. O narrador, explica Benjamin, "retira da experiência o que ele conta: sua própria experiência ou a relatada pelos outros. E incorpora as coisas narradas à experiência dos seus ouvintes" (BENJAMIN, 1987, p. 201). Essas experiências geralmente se consolidam quando estamos dispostos a contar e a revelar aquilo que se viveu. Ao lembrar somos afetados por outras lembranças que não escolhemos necessariamente. O verdadeiro lembrar é espontâneo, é algo que não se aprende. Ao voltar ao passado para construir o presente o homem confirma a sua necessidade de lembrar e a sua incapacidade de viver sem as lembranças e memórias do passado. O ato de rememorar, portanto, exerce um papel fundamental no processo de reconstrução da identidade individual e coletiva. Segundo Michael Pollak,

\begin{abstract}
A priori, a memória parece ser um fenômeno individual, algo relativamente íntimo, próprio da pessoa. Mas Maurice Halbwachs, nos anos 20-30, já havia sublinhado que a memória deve ser entendida também, ou sobretudo, como um fenômeno coletivo e social, ou seja, como um fenômeno construído coletivamente e submetido a flutuações, transformações, mudanças constantes. (POLLAK, 1992, p. 2)
\end{abstract}

Ao testemunhar com o outro a memória coletiva é ativada. Esse trabalho da memória só se fideliza quando estes que testemunham juntos encontram apoio e interação no coletivo. Para Kessel, a memória coletiva tem "uma importante função de contribuir para o sentimento de pertinência a um grupo de passado comum, que compartilha memórias" (KESSEL, 2009, p. 3). A experiência compartilhada da memória através da linguagem revela seu caráter 
social. Maurice Halbwachs explica a construção social dessa comunidade afetiva:

\begin{abstract}
Se nossa impressão pode apoiar-se não somente sobre nossa lembrança, mas também sobre a de outros, nossa confiança na exatidão de nossa evocação será maior, como se uma mesma experiência fosse começada, não somente pela mesma pessoa, mas por várias. (HALBWACHS, 1990, p. 25)
\end{abstract}

A memória é importante por que ela é um fator de construção, revelação da história e da identidade. No desenvolver a questão da memória, existe uma dependência do tempo presente para que as lembranças do passado sejam recordadas. "Como elaboração de variados estímulos, a memória é sempre uma construção feita no presente a partir de vivências/experiências ocorridas no passado" (KESSEL, 2009, p. 2). Embora a memória tenha o poder de rever o passado, ela não pode ser compreendida se não existir a ação no presente do sujeito que a recorda. É através da interação como o outro que as lembranças são ativadas. Percebe-se, então, que a memória é agente causador do confronto entre identidade, história e narração.

O revelar da história exige um processo de criatividade narrativa que, geralmente, demanda ordem, coerência e tempo sequencial. $E$ toda "explanação histórica", explica Hayden White, é "retórica e poética por natureza" (WHITE, 1995, p. 11). Revelamos a história quando construímos narrativas. A identidade, consequentemente, pode ser vista como uma questão de narrar a si mesmo. A manifestação do nosso eu interior e da força da impregnação das imagens que ficam gravadas em nossa alma (realidade psíquica), as "manipulações conscientes ou inconscientes que o interesse, a afetividade, o desejo, a inibição, a censura exercem sobre a memória individual" (LE GOFF, 1992, p. 422), a nossa relação com o mundo e as possibilidades de experiências que este nos condiciona, são fatores que cooperam na formação da nossa identidade. De acordo com Hall, "as identidades surgem, esteja, em parte, no imaginário (assim como no simbólico) e, portanto, sempre, em parte, construída na fantasia ou, ao menos, no interior de um campo fantasmático" (HALL, 2000, p. 109). É a nossa relação com o mundo e a forma que compreendemos essa relação que dão sentido e valor à 
existência. Afinal, "o simbolismo é o modo de nos relacionar com o mundo e a forma com que estruturamos nossa subjetividade" (RUIZ, 2003, p. 180).

Segundo o filósofo francês Paul Ricœur, a memória opera na "na esteira da imaginação" (RICOEUR, 2007, p. 25). Portanto, a memória está sujeita à traição e ao esquecimento. Para desencadeá-la é preciso que ela atravesse um processo criativo para preenchimento das lacunas trazidas pelo testemunho. Não podemos, porém, administrar a maneira como as lembranças são geradas em nós, não podemos controlar ou confiar em suas impressões, não há como saber quem são seus autores e como suas impressões são desenvolvidas. A capacidade e a atividade de lembrar é uma faculdade paradoxal, pois "o que já passou mantém sempre um relativo caráter de indecifrável" (PADRÓS, 1991, p.82). A memória depende das impregnações das imagens e lembranças que recordam o passado para que no tempo presente reconstrua aquilo que não mais existe. O filósofo e historiador da arte, Georges Didi-Huberman, ao analisar imagens feitas em Auschwitz-Birkenau, nos ensina que o lugar da nossa história está em saber analisar o passado de um ponto de vista arqueológico:

O fogo da história passou. Partiu como a fumaça dos crematórios, soterrado junto com as cinzas dos mortos. Isso significa que não há nada a imaginar porque não há nada - ou muito pouco - a ver? Certamente não. Olhar as coisas de um ponto de vista arqueológico é comparar o que vemos no presente, 0 que sobreviveu, com 0 que sabemos ter desaparecido. (HUBERMAN, 2013, p. 117)

O processo de lembrar abrange diferentes maneiras para interpretar os fatos do passado, essas recordações são representações do passado ligadas ao que vivemos no presente. É difícil reduzir o conceito em um único elemento, principalmente quando seu conteúdo é composto pelo temporal e é afetado por imagens e pela transitoriedade que atravessa a identidade humana. É a linguagem que firma o acordo social com a memória. Por isso, o ato de falar e escrever, o compor narrativas, nos mostra que a memória está intimamente ligada à questão da linguagem.

Se analisarmos, por exemplo, os testemunhos de judeus que escaparam dos campos de extermínio da Segunda Guerra Mundial, percebe-se que existe 
um esforço desses sobreviventes para manter vivas as suas lembranças e memórias traumáticas. Hannah Arendt nos explica que, "nenhuma permanência, nenhuma perseverança da existência podem ser concebidas sem homens decididos a testemunhar" (ARENDT, 1997, p. 285). Vários são os motivos que fazem alguém querer lembrar aquilo que se quer esquecer, e por não quererem que o mundo jamais esqueça o que aconteceu no Lager, as vítimas do Holocausto entenderam a urgência, a necessidade e o dever de registrar suas memórias traumáticas, de "transmitir e escrever as memórias dos mortos, dos vencidos, e não calar mais uma vez suas vozes" (GAGNEBIN, 2006, p. 11).

Os sobreviventes reconhecem a obrigação de resgatar a memória dos silenciados, de fazer vir à tona o indizível, dar voz àquele que foi produzido nos campos da morte e deixou de ser 'humano', porque a força do trauma que os acomete os desfigurou completamente, originando assim, uma cisão entre homem e não-homem. Essa força horrenda, que extraiu toda a saúde mental e física daqueles que restaram dos campos da morte, foi capaz de aniquilar nesses restos de homens a capacidade de proferir as atrocidades às quais foram submetidos. Esse "ser qualquer" é representado na figura do "muçulmano" (Muselmann), também conhecido por inumano ou o não-homem. Segundo Agamben, "o muçulmano é o não-homem que se apresenta obstinadamente como homem, e o humano que é impossível dissociar do inumano" (AGAMBEN, 2008, p. 87), seres que foram produzidos no campo de extermínio de Auschwitz, cujo testemunho é indizível, "o muçulmano é o segredo absolutamente não testemunhável" (AGAMBEN, 2008, p. 156). O muçulmano foi o semimorto massacrado no Lager, aquele que não conseguiu resistir às crueldades impostas nas fábricas da morte.

Segundo os arquivos do Centro de Pesquisa da Shoah em Jerusalém, Yad Vashem, o termo "muçulmano" foi amplamente utilizado entre os prisioneiros dos campos de extermínio para se referir aos presos que estavam perto da morte por exaustão, fome, ou desesperança. Devido à incapacidade de se firmar em pé por causa da perda dos músculos na perna, consequentemente ficavam a maior parte do tempo curvados. Alguns estudiosos acreditam que o termo se originou a partir dessa propensa 
semelhança de semimorto dos prisioneiros do Campo em relação à imagem de um muçulmano (Islamita) prostrando-se no chão em oração.

Muitas vítimas, faltando-lhes totalmente os recursos físicos e mentais para adaptar-se, alcançaram esse estado degradante logo após sua chegada ao Campo. Outros prisioneiros sucumbiram à doença, abuso físico, desnutrição e excesso de trabalho escravo. O muçulmano era facilmente identificado pelo seu declínio físico e psicológico. Letárgicos e indiferentes a todos a sua volta, não conseguiam ficar de pé por pouco mais que um curto período de tempo. A maioria dos outros prisioneiros evitava o contato com os muçulmanos com medo de contrair a condição desprezível e mortal destinadas a esses sujeitos.

Os nazistas que administravam os Campos consideravam os muçulmanos indesejáveis porque eles não podiam trabalhar ou suportar as regras do Campo. Por isso, durante as seleções, essas vítimas foram os primeiros a serem condenados à morte. Uma pessoa no estado de muçulmano não tinha nenhuma chance de sobrevivência. Ele ou ela não viveria além de alguns poucos dias ou semanas ${ }^{2}$.

Levi descreve em sua obra como os veteranos do Campo designavam os muçulmanos: "os fracos, os ineptos, os destinados à 'seleção". Eles eram os "homens próximos do fim", os que estavam ali apenas por um breve momento. Os que na "solidão morrem ou desaparecem sem deixar lembrança alguma na memória de ninguém". Os muçulmanos foram os selecionados para as câmaras de gás, ou seja, escolhidos para a morte, "simplesmente, acompanharam a descida até o fim, [...] foram esmagados antes de conseguir adaptar-se; ficaram para trás [...]" (LEVI, 1998, p. 129-132). Os muçulmanos foram aqueles que perderam a noção do que é padecer com resignação e paciência, aqueles que esqueceram o que é tolerar ou desistir de alguma coisa ou alguém. Afinal, conforme aponta Levi, não há como descrevê-los segundo os conceitos que caracterizam um ser humano normal:

[...] não-homens que marcham e se esforçam em silêncio; já se apagou neles a centelha divina, já estão tão vazios, que nem podem realmente sofrer. Hesita-se em chamá-los vivos; hesita-

\footnotetext{
${ }^{2}$ Disponível em: <http://www.yadvashem.org/odot_pdf/Microsoft\%20Word\%20-\%206474.pdf>. Acesso em: 27 nov. 2015.
} 
se em chamar 'morte' à sua morte, que eles já nem temem, porque estão esgotados demais para poder compreendê-la. (LEVI, 1998, p. 132)

O muçulmano torna-se, então, esse ser pejorativo e apático em relação a sua própria sorte, completamente inapto, "com sua presença sem rosto [...] um homem macilento, cabisbaixo, de ombros curvados, em cujo rosto, em cujo olhar, não se possa ler o menor pensamento." (LEVI, 1998, p. 132). Ele é a representação do limiar da vida biológica, o ser que não sonha e não tem esperança, pois sua realidade psíquica foi completamente aniquilada.

Então, como fazer eclodir o testemunho do emudecido, daquele cuja fala já não se faz ouvir, dos que tatearam o fundo, dos que não voltaram para contar, dos que sucumbiram sufocados pelo Zyklon B? Como enunciar o indizível e fazer vir à tona as memórias que padeceram junto aos corpos nus incinerados nos fornos de gente? Como fazer ressurgir as memórias soterradas e apagadas nas valas sombrias do Lager? Como validar o testemunho do choque e do horror indescritível das vítimas da Shoah?

A partir da semântica da enunciação elaborada pelo linguista francês Émile Benveniste e dialogando com a obra de Michel Foucault, A arqueologia do saber (1969), Agamben nos ajuda a compreender alguns aspectos relacionados à questão da enunciação, cujas características estão diretamente associadas ao fato do que se está dizendo, ao acontecimento da linguagem e ao discurso em ato. Agamben nos explica que o enunciado não é uma estrutura, mas uma função de existência. É onde a linguagem acha lugar. Onde "o sujeito é um lugar determinado e vazio que pode ser efetivamente ocupado por diferentes indivíduos" (AGAMBEN, 2008, p. 142). Sendo assim, podemos afirmar que o enunciado acontece no lugar. $O$ sujeito então assume o status de ser ocupado por quem o deseje representar. Para Agamben, "o sujeito é, sobre tudo, o campo de forças sempre já atravessado pelas correntes incandescentes e historicamente determinadas da potência e da impotência, do poder não ser e do não poder não ser" (AGAMBEN, 2008, p. 148-149). Esse ciclo que envolve potência e impotência no ato da fala, dizer e não dizer, ou, dizível e indizível, gera a possibilidade do testemunho, ainda que ele não 
garanta a "verdade fatual do enunciado conservado no arquivo", mas garante sim, a sua "não-arquivabilidade" (AGAMBEN, 2008, p. 157).

Por isso o muçulmano é a testemunha integral, pois "o testemunho vale essencialmente por aquilo que nele falta" (AGAMBEN, 2008, p. 43). O que restou dos muçulmanos permanece para assumir a eternidade nas palavras dos sujeitos que produzem testemunhos por eles. De acordo com Agamben, "dar testemunho significa pôr-se na própria língua na posição dos que a perderam, situar-se em uma língua viva como se fosse morta, ou em uma língua morta como se fosse viva" (AGAMBEN, 2008, p.160). A testemunha se faz no que restou da possibilidade e da impossibilidade de dizer, ou seja, "o testemunho do sobrevivente é verdadeiro e tem razão de ser unicamente se vier a integrar o de quem não pode dar testemunho" (AGAMBEN, 2008, p. 151).

Muitos dos que narraram ou tem suas memórias traumáticas relatadas por uma testemunha, expõem suas feridas não apenas para documentar ou preservar a verdade factual do período histórico vivido, mas também para evocar suas subjetividades. A lembrança de cada sobrevivente da Shoah pertence unicamente a eles. Benjamin enfatiza que, "tudo que é lembrado, pensado, conscientizado, torna-se alicerce, moldura, pedestal, fecho de seus pertences" (BENJAMIN, 1987, p. 228). Apesar da tentativa dos nazistas de destruir a identidade do povo judeu através da força do anonimato que lhes foram impostos, a narrativa testemunhal dos sobreviventes do Holocausto mostra a força da memória em resgatar a identidade de toda uma nação.

A maneira como os sobreviventes do Holocausto expõem suas lembranças é carregada de propriedades únicas e intransferíveis. Para o escritor e sobrevivente do campo de concentração Elie Wiesel, "somente aqueles que experimentaram Auschwitz sabem o que é isso. Os outros nunca irão saber" (WIESEL, 2006, p. ixe). Por isso, cabe a esses sobreviventes recordar e expor suas lembranças como melhor lhes convier. Para os que observam a história e as histórias de longe, ficam os diferentes rastros, os vestígios da possibilidade de uma certeza objetiva deixada pelos fatos de uma memória subjetiva. Podemos dizer, então, que cada ser humano sobrevivente do Holocausto viveu seu próprio "Auschwitz". Sendo assim, os traumas 
herdados nos campos da morte produzem lembranças difíceis de serem atestadas, mas nem por isso, podem ser tratadas como inverdades.

Aferir verdades ou confiar nas memórias de uma mente traumatizada gera desconfiança e uma apreensão desfavorável a respeito daqueles que narram seus testemunhos. Uma vez que não podemos ter acesso ao passado, a possibilidade de se contestar a veracidade dos relatos memorialísticos é real. Paul Ricœur nos explica que a memória e a imagem trazem o cunho da suspeita.

Deve haver, na experiência viva da memória, um rastro irredutível que explique a insistência da confusão comprovada pela expressão imagem-lembrança. Parece, mesmo que a volta da lembrança pode fazer-se somente no modo do tornarse-imagem. [...] A permanente ameaça de confusão entre rememoração e imaginação, que resulta desse tornar-seimagem da lembrança, afeta a ambição de fidelidade na qual se resume a função veritativa da memória. E no entanto, nada temos de melhor que a memória para garantir que algo ocorreu antes de formarmos sua lembrança. (RICCEUR, 2007, p. 26)

A memória é responsável pela impossibilidade de esquecer, porém, ela está permeada de obstáculos, sendo a "crescente instabilidade do tempo" e o "fraturamento do espaço vivido" (HUYSSEN, 2000, p. 20) os protagonistas responsáveis por causar a falta de exatidão das lembranças do passado. Essa falha da memória passa a exercer papel fundamental no processo de criação da narrativa. Aqueles que testemunharam o horror trazem em suas narrativas a mistura das imprecisões de suas experiências, fazendo com que as lembranças dos fatos vividos transitem entre o real e o imaginário. Eventos realmente vividos são muitas vezes agrupados com histórias alheias e a origem testemunhal das memórias traumáticas dos sobreviventes da Shoah, consequentemente, resulta na verdade factual e subjetiva do texto narrado.

Por outro lado, existe o risco da contradição testemunhal que é fruto do apagamento dos rastros, onde o depoimento de um mesmo fato pode ser ouvido e conhecido diferentemente por quem o observou. É importante salientar que as testemunhas não têm a intenção de fraudar ou corromper os fatos, mas o desejo de reconstruí-los. Segundo Seligmann-Silva, "o testemunho também é um momento de tentativa de reunir os fragmentos dando um nexo e 
um com-texto aos mesmos" (SELIGMANN-SILVA, 2001, p. 124). É a restrição da mente humana em rememorar as experiências do passado, que traz, nas palavras de Ricœur, "o cunho da suspeita". E isso, nos leva a admitir a probabilidade de existir novas formas de interpretação do fato que se imagina ser a verdade. Porém, os problemas que abrangem os aspectos que aferem a veracidade dos testemunhos escritos ou falados não estão limitados ou baseados a um único conceito. A abordagem da análise da narrativa testemunhal pode ser objetiva e baseada em fatos, como também, subjetiva, baseada em meros valores pessoais, culturais e coletivos. Por isso, ao lidar com a questão da memória, se aceita o risco de contestar a consciência para mostrar que o consciente nem sempre condiz com o que aparenta ser. A constante escolha daquilo que se quer lembrar é de certa forma um ato de reinventar o passado. Lidamos, então, com verdades factuais e subjetivas. As narrativas memorialísticas nos movem a refletir sobre os problemas referentes ao processo de recordar e o dever de narrar histórias, os quais são parte integral do trabalho literário.

\section{Considerações finais}

$\mathrm{O}$ ato de usar a linguagem para representar a memória, o trauma e as complicações que envolvem a reconstrução do passado, pode influenciar e restringir a abordagem do discurso historiográfico do presente. Para Benjamin, "articular historicamente o passado não significa conhecê-lo 'como ele de fato foi'. Significa apropriar-se de uma reminiscência, tal como ela relampeja no momento de um perigo" (BENJAMIN, 1994, p. 224). O passado é articulado e não descrito. Ao procurar estabelecer a história verdadeira através do uso da linguagem, essa pode ser imprecisa ou insuficiente para construir o passado. Os rastros se perdem ou são apagados ao longo do tempo. Mas o que de fato importa é como abordamos os acontecimentos passados para se fazer o presente através da tentativa de decifrar o enigma no qual o estudo da memória se permeia. É preciso olhar para o passado com o intuito de buscar nele os sentidos e afetos necessários que tornam os desafios e a sobrevivência no presente possível. Afinal, acrescenta Benjamim, a "história é objeto de uma 
construção cujo lugar não é o tempo homogêneo e vazio, mas aquele preenchido pelo tempo-agora" (GAGNEBIN, 2006, p. 41).

\section{REFERÊNCIAS}

AGAMBEN, Giorgio. O que resta de Auschwitz. Homo sacer III. Trad. bras. Selvino J. Assmann. São Paulo: Boitempo, 2008.

ARENDT, Hannah. Entre o Passado e o Futuro. Tradução de Mauro W. Barbosa de Almeida. São Paulo: Perspectiva, 1997.

BENJAMIN, Walter. Magia e técnica, arte e política: ensaios sobre literatura e história da cultura. Trad. Sérgio Paulo Rouanet. São Paulo: Brasiliense, 1993. (Obras escolhidas; v. 1)

. Sobre o conceito de história. In: Magia e técnica, arte e política: ensaios sobre literatura e história da cultura. Trad. Sérgio Paulo Rouanet. São Paulo: Brasiliense, 1987, pp. 222-234. (Obras escolhidas; v. 1)

Rua de Mão Única. Trad. R. Rodrigues Torres Filho e J. C. Martins Barbosa. São Paulo: Brasiliense, 1987. (Obras escolhidas; v. 2) DERRIDA, Jacques. Anne Dufourmantelle convida Jacques Derrida a falar da hospitalidade. Trad. Antonio Romane. São Paulo: Escuta, 2003.

Mal de Arquivo: Uma Impressão Freudiana. Trad. Cláudia de Morais Rego. Rio de Janeiro, Relume Dumará, 2001.

DIDI-HUBERMAN, Georges. Cascas. Revista Serrote. São Paulo: Instituto Moreira Salles, n. 13, p. 100, mar. 2013.

GAGNEBIN, J. M. Lembrar, escrever, esquecer. São Paulo: 34, 2006.

HALL, Stuart. Quem precisa da identidade? In: SILVA, Tomas Tadeu da (org.). Identidade e diferença. A perspectiva dos estudos culturais. Petrópolis: Vozes, 2000, pp. 103-133.

HALBWACHS, Maurice. A memória coletiva. São Paulo: Vértice, 1990.

HUYSSEN, Andreas. Seduzidos pela memória: arquitetura, monumentos, mídia. Rio de Janeiro: Aeroplano, 2000. 
KESSEL, Zilda. Memória e memória coletiva. Disponível em: <www.museudapessoa.net/.../zilda_kessel_memoria_e_memoria_coletiva.pdf $>$. Acesso em: 22 jul. 2009.

LE GOFF, Jacques. Memória. In: LE GOFF, Jacques. História e memória. 2. ed., trad. de Irene Ferreira (et al.), Campinas, SP: Editora da UNICAMP, 1992, pp. 419-476.

LEVI, Primo. É isto um homem? Trad. Luigi Del Re, Rio de Janeiro: Rocco, 1988.

MERCADO, Tununa. Testemunho, Verdade e literatura. In: GALLE, Helmut (et al.) (org.). Em primeira pessoa: abordagens de uma teoria da autobiografia. São Paulo: Annablume; FAPESP; FFLCHUSP, 2009, pp. 31-36.

PADRÓS, Enrique Serra. Usos da Memória e do Esquecimento na História. Letras, n. 22: "Literatura e Autoritarismo", Santa Maria/RS, p. 79-95, jan./jun. 1991.

POLLAK, Michael. Memória e identidade social. Estudos Históricos, v. 5, n. 10, Rio de Janeiro, pp. 200-212, 1992. Disponível em: http://www.cpdoc.fgv.br/revista/arq/104.pdf; Acesso em: 08 jul. 2009.

RICOEUR, Paul. A memória, a história, o esquecimento. Trad. Alain François [et al.]. São Paulo: Editora da UNICAMP, 2007.

RUIZ, Castor Bartolomé. Os Paradoxos do Imaginário. São Leopoldo, RS: Ed. Unisinos, 2003.

SELIGMANN-SILVA, Márcio. "Zeugnis" e "Testimonio": um caso de intraduzibilidade entre conceitos. Letras, n. 22: "Literatura e Autoritarismo", Santa Maria, RS, pp. 121-130, jan./jun. 2001.

WHITE, Hayden. A poética da história. In: WHITE, Hayden. Meta-história: a imaginação histórica do século XIX. São Paulo: Editora da Universidade de São Paulo, 1995, p. 11.

YAD VASHEM. Disponível em: <http://www.yadvashem.org/odot_pdf/Microsoft\%20Word\%20-\%206474.pdf>. Acesso em: 05 set. 2015. 